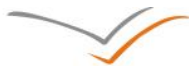

\title{
VERSITA
}

\section{Forecasting Future Salaries in the Czech Republic Using Stochastic Modelling}

\author{
Ondřej Šimpach and Jitka Langhamrová
}

Faculty of Informatics and Statistics, University of Economics in Prague, Czech Republic

\section{Abstract}

Background: In spite of the course of the economic crisis of 2008, there have not been changes dramatic to the extent that they would strongly alter the behaviour of the trend in the Average Gross Monthly Wages and the Monthly Wage Medians in the Czech Republic. In order to support public and monetary planning, reliable forecasts of future salaries are indispensable. Objectives: The aim is to provide an outline of the behaviour of the average gross wages and the gross wage medians of the Czech business sphere up to the end of 2018 using an optimised random walk model and an optimised ARIMA Model with a constant. Methods: Consumer price indices were used in the confrontation of the behaviour of the Average Gross Monthly Wages and the Monthly Wage Medians with the behaviour of inflation in the Czech Republic. The Box-Jenkins methodology is used for the time series modelling. Results: The Czech Average Gross Monthly Wages and the Monthly Wage Medians in the business sector will continue to grow more rapidly than the Czech inflation growth, expressed by consumer price indices. Conclusions: It is possible to expect that the rising trend of the Average Gross Monthly Wages and the Gross Wage Medians will be more rapid than the growth of inflation.

Keywords: Random walk, ARIMA, Average Gross Monthly Wage, Monthly Wage Medians, Consumer Price Index, stochastic trend

JEL main category: Macroeconomics and Monetary Economics

JEL classification: C22, E24

Paper type: Research article

Received: 19, December, 2012

Revised: 12, April, 2013

Accepted: 11, June, 2013

Citation: Šimpach, O., Langhamrová, J. (2013), "Forecasting Future Salaries in Czech Republic using Stohastic Modelling", Business Systems Research, Vol. 4, No. 2, pp.4-16.

DOI: 10.2478/bsri-2013-0009

Acknowledgements: The study was prepared under the project of University of Economics Prague IGA 29/2011 "Analysis of aging and the impact on the labour market and economic activity".

\section{Introduction}

Stochastic modelling may seem to be a simple instrument, nevertheless in the dynamic world of a developing economy, including that of the Czech Republic (Bucevska, 2012), the assumptions of even far more complicated models for estimating the future trend of economic time series may be very easily infringed (Smrčka et al., 2012). The past shows us that, in spite of the course of the economic crisis of 2008 (Jeřábková et al., 2011), there have not been any changes so dramatic that they would strongly alter the behaviour of the trend 
in Average Gross Monthly Wages and Monthly Wage Medians. The decline was only temporary, not permanent. The constant increase in the aggregate price level in time and with it the constant rise in Average Gross Monthly Wages and Monthly Wage Medians can be assumed for the future with roughly the same probability as the rise in fuel prices and other economically precious raw materials (Ivanov et al., 2013). The Czech Republic is, according to the valid classification of the European Statistical Office (EUROSTAT), still classified as a developing economy. Such economy has the advantage to recover faster from the economic slowdown compared to the economically more developed countries (Okafor et al., 2010; Montiel et al., 2006). After the impact of the economic slowdown in the Czech Republic, the problems of financial indiscipline and restricted access to financial markets (Pejić-Bach, 2003) did not occur, which helped to accelerate the return to equilibrium.

Authors compare the inequality of the Average Gross Monthly Wages between the Czech business and non-business sector, using sophisticated approach of modelling of seasonal time series (Langhamrová et al., 2012; Šimpach et al., 2012). If we compare the evolution of income in the business and non-business sector in the Czech Republic, we find the significant inequality between them, especially at the times economic slowdown. The behaviour of income is usually described using the average wages. Unfortunately, the average is not robust statistics, which often leads to significant misalignment of observed variable (van den Berg et al., 2012). For this reason, in recent times, wage medians are used for analysing the income statistics.

For the requirements of the analysis we shall consider the time series of the Average Gross Monthly Wages and Monthly Wage Medians with quarterly frequency, published by ISAE (Information System on Average Earnings) and also the time series of consumer price indices with quarterly frequency, published by the CZSO (Czech Statistical Office). All the time series considered start with the 1st quarter of 2002 and end with the last quarter of 2010. The methodological approach used will be that of authors Box and Jenkins (1970) for the modelling of time series, especially the ARIMA Model and the Random Walk Model. On the basis of these models, we shall outline the behaviour of the average gross monthly wages, wage medians and consumer price indices up to the end of 2018. This behaviour will be important in particular for the requirements of interested subjects, who will then be able more easily to create their adaptive expectations (Evans et al., 2001; Shepherd, 2012).

In order to estimate the behaviour of Average Gross Monthly Wages and Monthly Wage Medians in comparison with the behaviour of Czech inflation, the indices of Average Gross Monthly Wages and of Monthly Wage Medians will be calculated on the basis of the average for 2005. Results indicate that it is possible to expect that the rising trend of Average Gross Monthly Wages and Monthly Wage Medians will be more rapid than the growth of inflation. Simple conclusion emerges that the Czech business sector need not, providing ceteris paribus, directly fear the devaluation of wages through inflation, as the growth of inflation is expected to be slower.

\section{Methodology}

For the requirements of the comparison of the behaviour of the Consumer Price Indices with the behaviour of Average Gross Monthly Wages, or with the behaviour of Monthly Wage Medians, an average will be calculated from the values for the observations from the 1st quarter of 2005 - 4th quarter of 2005. This value will be used for calculation of the indices of Average Gross Monthly Wages (AGMW), and the indices of Monthly Wage Medians (MWM). The calculation of indices of Average Gross Monthly Wages is given by subsequent formula

$$
I_{q, t}^{A G M W}=\frac{A G M W_{q, t}}{\left(\frac{A G M W_{1 Q 2005}+\cdots+A G M W_{4 Q 2005}}{4}\right)} \cdot 100[\%]
$$

and the calculation of indices of Monthly Wage Medians is given by formula

$$
I_{q, t}^{M W M}=\frac{M W M_{q, t}}{\left(\frac{M W M_{1 Q 2005}+\cdots+M W M_{4 Q 2005}}{4}\right)} \cdot 100[\%]
$$


Since we used the same base for all indices (average of $2005=100 \%$ ), it is possible to compare them with each other. These indices, obtained from the ARIMA Model and the Random Walk Model, will be confronted with the values of the consumer price indices in a multiple X-Y plot.

\section{Modelling the average gross monthly wages and monthly wage medians}

On the basis of the methodological approach of the authors Box and Jenkins (1970), we identified the ARIMA Model $(1,1,1)$ with constant for the times series Average Gross Monthly Wages and further the Random Walk Model with drift, where the drift was optimised at the value 273.457. The drift was calculated by an iterative method in the system Statgraphics Centurion XVI, version 16.1.11. The estimates of the parameters of the ARIMA $(1,1,1)$ Model with constant are given in Table 1.

The diagnostic tests of the model indicate that the non-systematic component of the model is not auto-correlated. It is homoscedastic, and has normal distribution (Engle, 1995; Jarque et al., 1980). Using the ARIMA $(1,1,1)$ model with constant and the Random Walk Model with a drift of 273.457, we calculated the predictions up to the end of 2018, which are depicted in Figure 1 and Figure 2. It is evident that both models provide comparable results, albeit the intervals of reliability in the ARIMA Model are somewhat narrower.

Table 1

Estimates of parameters of the ARIMA $(1,1,1)$ model with constant for the times series Average Gross Monthly Wages

\begin{tabular}{lllll}
\hline Parameter & Estimate & Stnd. Error & T-Statistic & $P$-value \\
\hline AR(1) & -0.982392 & 0.0573603 & -17.1267 & 0.000000 \\
MA(1) & -0.807264 & 0.134941 & -5.98235 & 0.000001 \\
Mean & 266.198 & 54.5818 & 4.87704 & 0.000028 \\
\hline
\end{tabular}

Source: Author's calculation

Figure 1

Behaviour of Average Gross Monthly Wages (in CZK) from the 1st q. Of 2002 to the 4th q. Of 2010 with calculated predictions up to the 4th q. of 2018 using the ARIMA Model

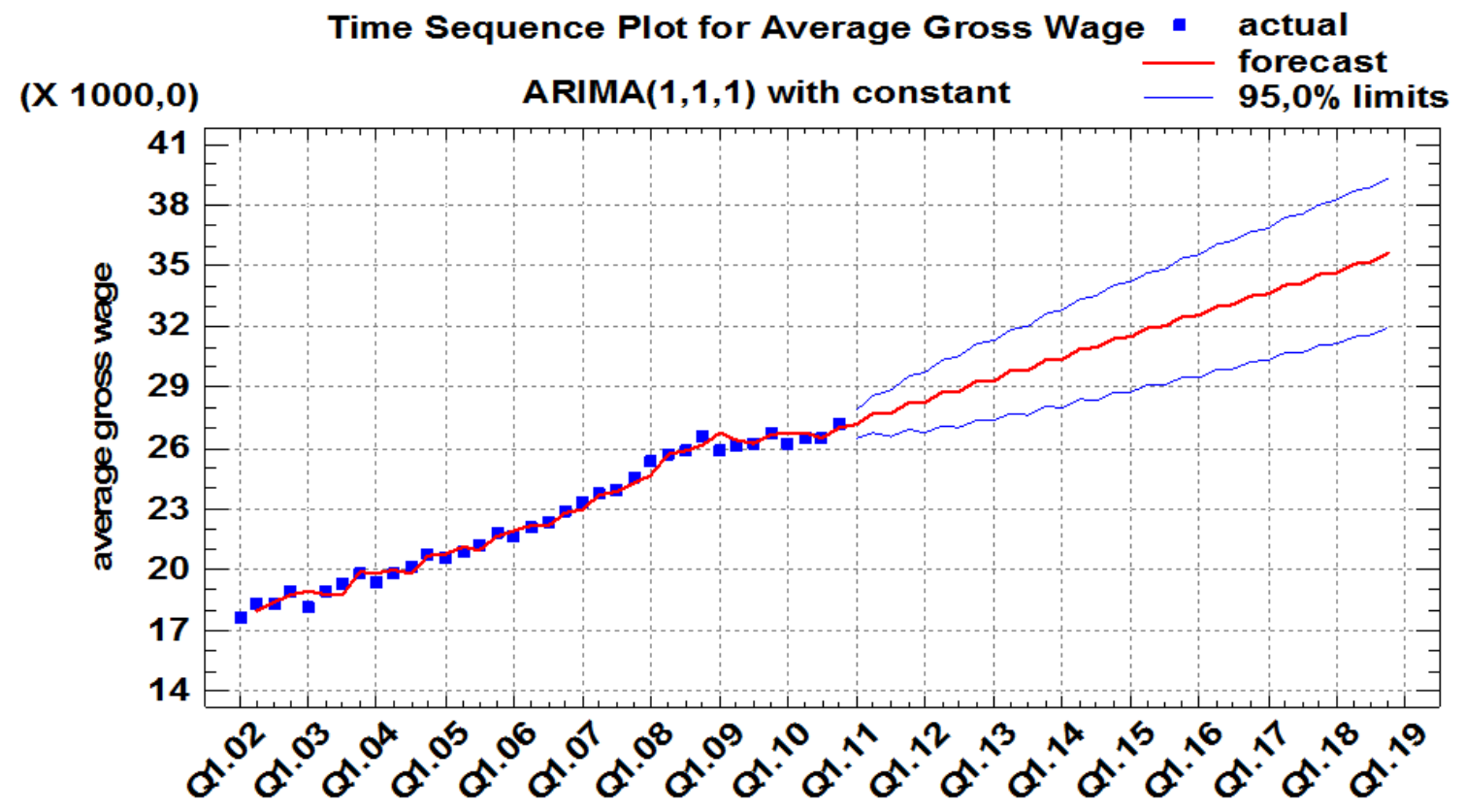

Source: ISAE, Author's illustration 
Figure 2

Behaviour of Average Gross Monthly Wages (in CZK) from the 1st q. of 2002 to the 4th q. of 2010 with calculated predictions up to the 4th q. of 2018 using the Random Walk with drift

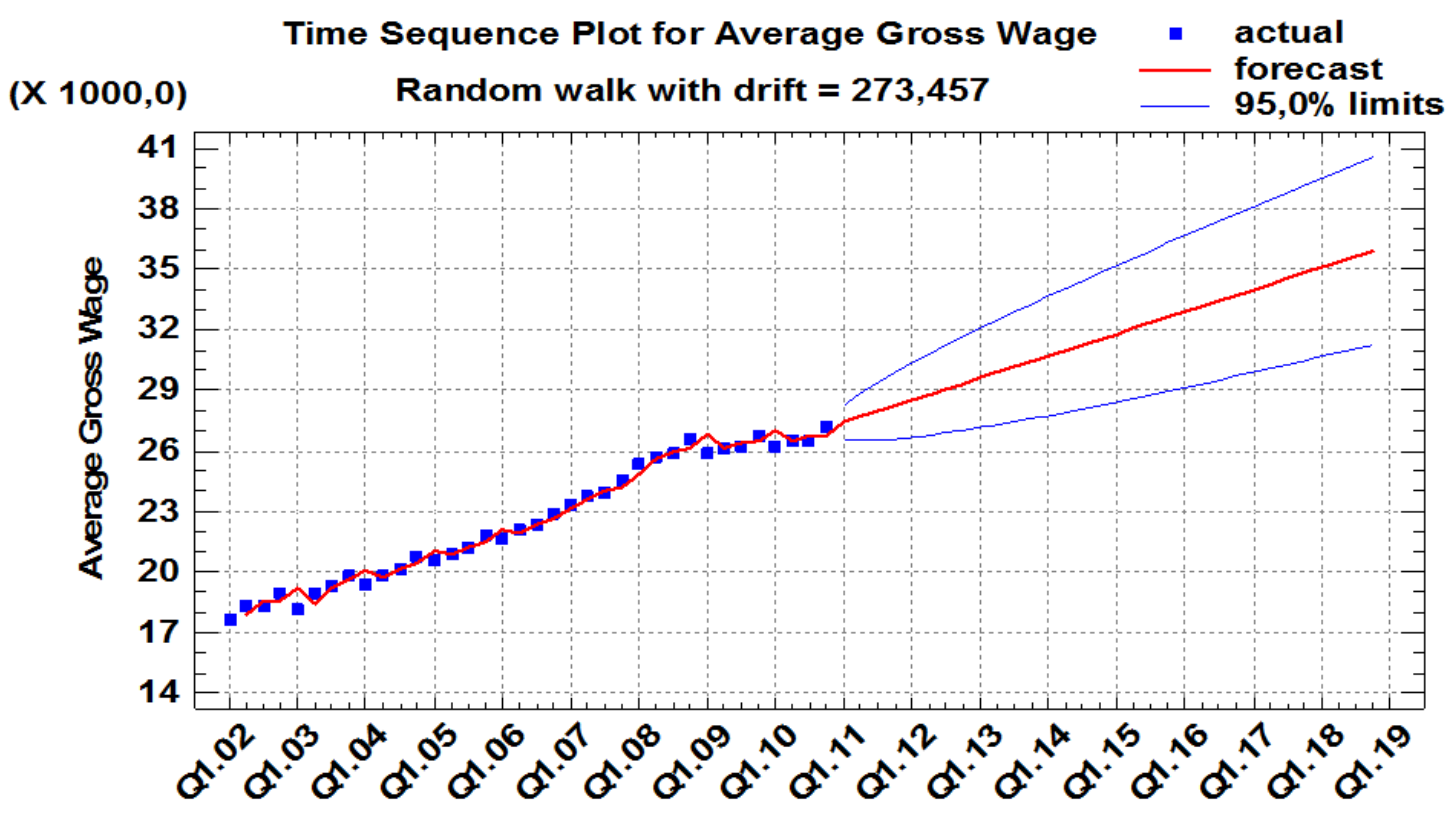

Source: ISAE, Author's illustration

Table 2 provides forecasts of Average Gross Monthly Wages using ARIMA Model, and Table 3 provides forecasts of Average Gross Monthly Wages using the Random Walk Model with drift. Values expressed in Czech crowns were converted to values in Euro, using the conversion rate 1 EUR=25.06 CZK, which was set according to the Czech National Bank (CNB) at $31 / 12 / 2010$.

Table 2

Forecasts of Average Gross Monthly Wages Using ARIMA model (in CZK and EUR, conversion rate was set according to the Czech National Bank (CNB) at 31/12/2010 1 EUR=25.06 CZK)

\begin{tabular}{|c|c|c|c|c|c|c|c|c|}
\hline Period & CZK & EUR & Period & CZK & EUR & Period & CZK & EUR \\
\hline Q1.10 & 26792,6 & 1069,14 & Q1.13 & 29322,0 & 1170,07 & Q1.16 & 32536,7 & 1298,35 \\
\hline Q2.10 & 26784,7 & 1068,82 & Q2.13 & 29797,8 & 1189,06 & Q2.16 & 32972,2 & 1315,73 \\
\hline Q3.10 & 26496,4 & 1057,32 & Q3.13 & 29858,1 & 1191,46 & Q3.16 & 33072,1 & 1319,72 \\
\hline Q4.10 & 27008,1 & 1077,74 & Q4.13 & 30326,6 & 1210,16 & Q4.16 & 33501,7 & 1336,86 \\
\hline Q1.11 & 27176,3 & 1084,45 & Q1.14 & 30394,1 & 1212,85 & Q1.17 & 33607,3 & 1341,07 \\
\hline Q2.11 & 27684,1 & 1 104,71 & Q2.14 & 30855,5 & 1231,26 & Q2.17 & 34031,3 & 1357,99 \\
\hline Q3.11 & 27713,0 & 1105,87 & Q3.14 & 30929,9 & 1234,23 & Q3.17 & 34142,5 & 1362,43 \\
\hline Q4.11 & 28212,3 & 1125,79 & Q4.14 & 31384,5 & 1252,37 & Q4.17 & 34560,9 & 1379,13 \\
\hline Q1.12 & 28249,5 & 1 127,27 & Q1.15 & 31465,6 & 1255,61 & Q1.18 & 34677,6 & 1383,78 \\
\hline Q2.12 & 28740,6 & 1146,87 & Q2.15 & 31913,6 & 1273,49 & Q2.18 & 35090,7 & 1400,27 \\
\hline Q3.12 & 28785,8 & 1148,68 & Q3.15 & 32001,2 & 1276,98 & Q3.18 & 35212,6 & 1405,13 \\
\hline Q4.12 & 29269,1 & 1167,96 & Q4.15 & 32442,9 & 1294,61 & Q4.18 & 35620,5 & 1421,41 \\
\hline
\end{tabular}

Source: Author's calculation 
Table 3

Forecasts of Average Gross Monthly Wages using Random Walk Model; conversion rate was set according to the Czech National Bank (CNB) at 31/12/2010 1 EUR $=25.06$ CZK

\begin{tabular}{lllllllll}
\hline Period & CZK & EUR & Period & CZK & EUR & Period & CZK & EUR \\
\hline Q1.10 & 26997,5 & 1077,31 & Q1.13 & 29617,1 & 1181,85 & Q1.16 & 32898,6 & 1312,79 \\
Q2.10 & 26498,5 & 1057,40 & Q2.13 & 29890,6 & 1192,76 & Q2.16 & 33172,1 & 1323,71 \\
Q3.10 & 26735,5 & 1066,86 & Q3.13 & 30164,0 & 1203,67 & Q3.16 & 33445,5 & 1334,62 \\
Q4.10 & 26791,5 & 1069,09 & Q4.13 & 30437,5 & 1214,58 & Q4.16 & 33719,0 & 1345,53 \\
Q1.11 & 27429,5 & 1094,55 & Q1.14 & 30710,9 & 1225,49 & Q1.17 & 33992,4 & 1356,44 \\
Q2.11 & 27702,9 & 1105,46 & Q2.14 & 30984,4 & 1236,41 & Q2.17 & 34265,9 & 1367,35 \\
Q3.11 & 27976,4 & 1116,38 & Q3.14 & 31257,9 & 1247,32 & Q3.17 & 34539,3 & 1378,26 \\
Q4.11 & 28249,8 & 1127,29 & Q4.14 & 31531,3 & 1258,23 & Q4.17 & 34812,8 & 1389,18 \\
Q1.12 & 28523,3 & 1138,20 & Q1.15 & 31804,8 & 1269,15 & Q1.18 & 35086,3 & 1400,09 \\
\hline Q2.12 & 28796,7 & 1149,11 & Q2.15 & 32078,2 & 1280,06 & Q2.18 & 35359,7 & 1411,00 \\
Q3.12 & 29070,2 & 1160,02 & Q3.15 & 32351,7 & 1290,97 & Q3.18 & 35633,2 & 1421,92 \\
Q4.12 & 29343,7 & 1170,94 & Q4.15 & 32625,1 & 1301,88 & Q4.18 & 35906,6 & 1432,83 \\
\hline
\end{tabular}

Source: Author's calculation

The use of Monthly Wage Medians is suitable for expression of the wage differentiation of the Czech Republic, as more than $60 \%$ of the population is already receiving a belowaverage wage. A Monthly Wage Medians is a more robust statistic, which is less encumbered by remote values (Zelený, 2001). In a similar way to that used in the case of the time series Average Gross Monthly Wages we identified the ARIMA $(2,1,2)$ model with constant and further the Random Walk Model with drift for the time series Monthly Wage Medians. The drift was optimised at the value of 212.171. The drift was calculated by an iterative method in the system Statgraphics Centurion XVI, version 16.1.11. The estimated parameters of the ARIMA (2, $1,2)$ model with constant are given in Table 4.

Table 4

Estimated parameters of ARIMA $(2,1,2)$ model with constant for the time series Monthly Wage Medians

\begin{tabular}{lllll}
\hline Parameter & Estimate & Stnd. Error & T-Statistic & P-value \\
\hline AR(1) & 0.39407 & 0.15897 & 2.4789 & 0.019025 \\
AR(2) & -0.646481 & 0.16629 & -3.88766 & 0.000519 \\
MA(1) & 1.02827 & 0.143553 & 7.16302 & 0.000000 \\
MA(2) & -0.887883 & 0.107661 & -8.24701 & 0.000000 \\
\hline Mean & 195.766 & 51.4061 & 3.80822 & 0.000645 \\
\hline Constant & 245.179 & & & \\
\hline
\end{tabular}

Source: Author's calculation

Again, the diagnostic tests of the model are statistically significant on the $5 \%$ level of significance. Using the ARIMA $(2,1,2)$ model with constant and the random walk model with a drift of 212.171, we calculated predictions up to the end of 2018, which are depicted in Figure 3 and Figure 4. Table 5 provides forecasts of monthly wage medians using ARIMA Model. Table 6 provides forecasts of Monthly Wage Medians using the Random Walk Model with drift.

When comparing the values of the Average Gross Monthly Wages and Monthly Wage Medians, it is clear that the Monthly Wage Medians are in each observation of about 19.25 to $20.66 \%$ lower than the Average Gross Monthly Wages. 
Figure 3

Behaviour of Monthly Wage Medians (in CZK) from 1st q. of 2002 to 4th q. of 2010 with calculated predictions up to the 4th q. of 2018 using the ARIMA Model

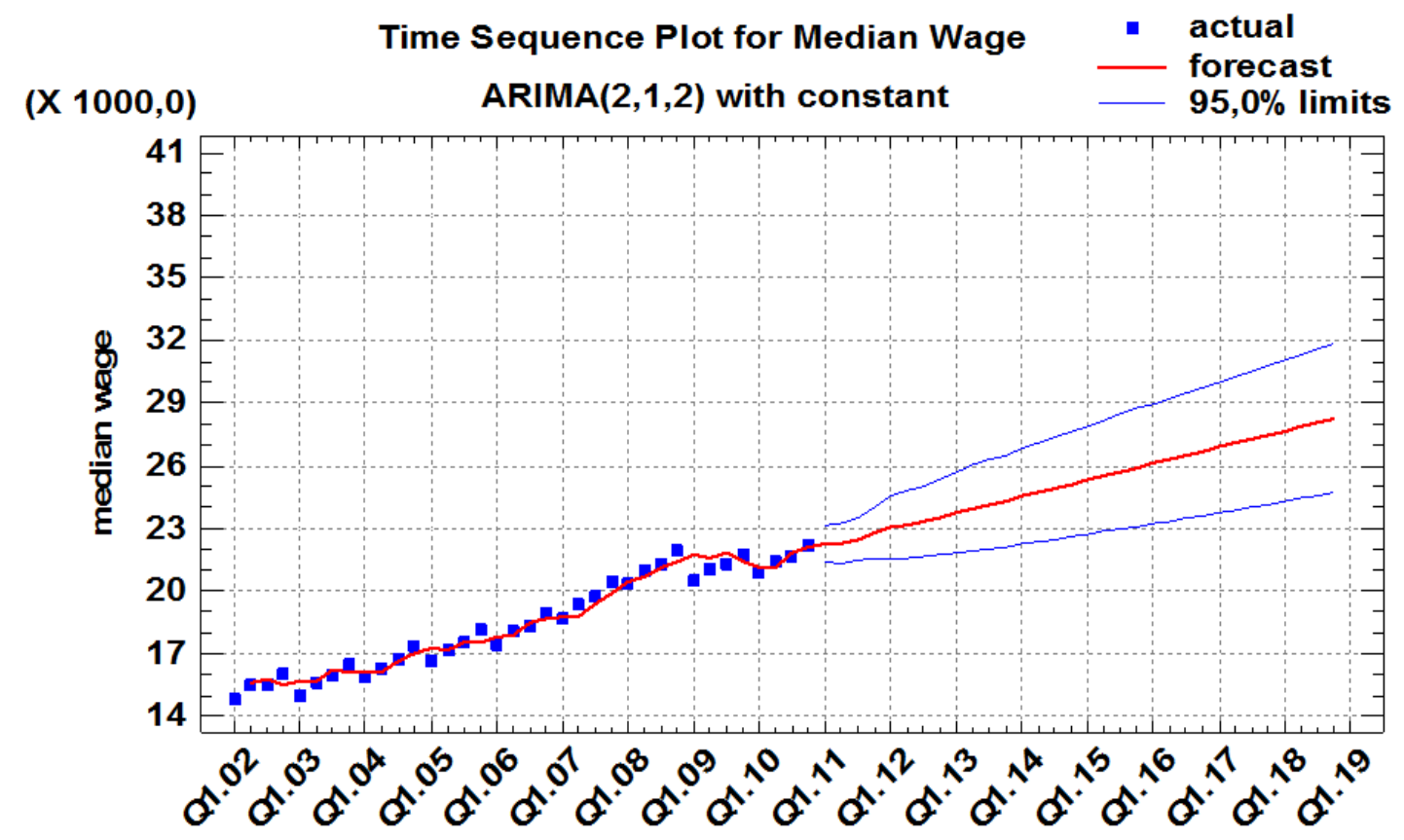

Source: ISAE, Author's illustration

Figure 4

Behaviour of Monthly Wage Medians (in CZK) from 1st q. of 2002 to 4th q. of 2010 with calculated predictions up to the 4th q. of 2018 using the Random Walk Model with drift

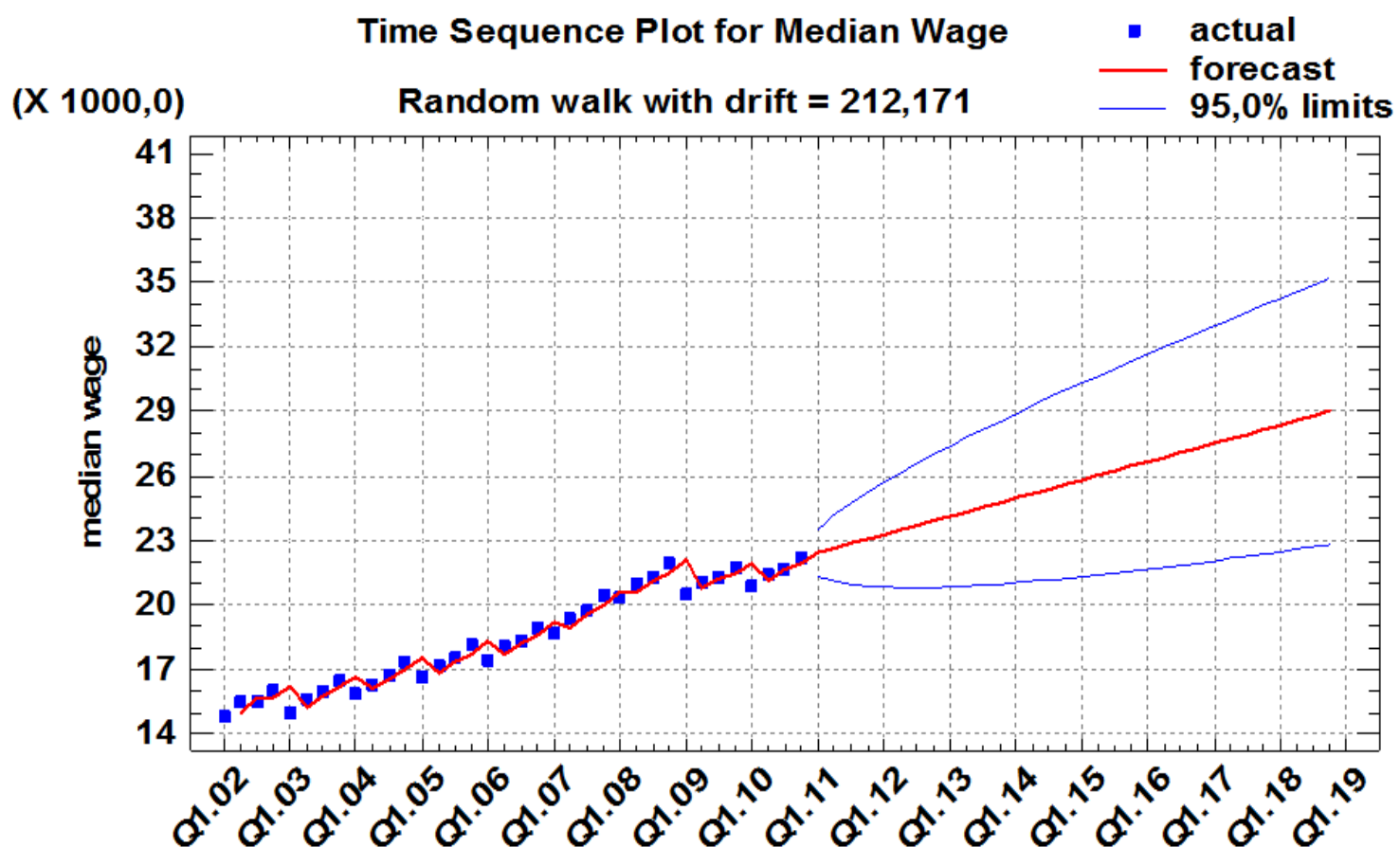

Source: ISAE, Author's illustration 
Table 5

Forecasts of Monthly Wage Medians using ARIMA model; Conversion rate was set according to the Czech National Bank (CNB) at 31.12.2010 1 EUR $=25.06 \mathrm{CZK}$

\begin{tabular}{lllllllll}
\hline Period & CZK & EUR & Period & CZK & EUR & Period & CZK & EUR \\
\hline Q1.10 & 21153,2 & 844,10 & Q1.13 & 23777,0 & 948,80 & Q1.16 & 26107,0 & 1041,78 \\
Q2.10 & 21085,3 & 841,39 & Q2.13 & 23978,4 & 956,84 & Q2.16 & 26302,8 & 1049,59 \\
Q3.10 & 21819,0 & 870,67 & Q3.13 & 24148,8 & 963,64 & Q3.16 & 26500,6 & 1057,49 \\
Q4.10 & 22126,6 & 882,94 & Q4.13 & 24330,8 & 970,90 & Q4.16 & 26697,1 & 1065,33 \\
Q1.11 & 22286,4 & 889,32 & Q1.14 & 24537,7 & 979,16 & Q1.17 & 26891,9 & 1073,10 \\
Q2.11 & 22290,3 & 889,48 & Q2.14 & 24746,6 & 987,49 & Q2.17 & 27086,8 & 1080,88 \\
Q3.11 & 22485,8 & 897,28 & Q3.14 & 24940,5 & 995,23 & Q3.17 & 27282,8 & 1088,70 \\
Q4.11 & 22805,4 & 910,03 & Q4.14 & 25126,9 & 1002,67 & Q4.17 & 27479,3 & 1096,54 \\
Q1.12 & 23050,2 & 919,80 & Q1.15 & 25320,3 & 1010,39 & Q1.18 & 27675,1 & 1104,35 \\
\hline Q2.12 & 23185,2 & 925,19 & Q2.15 & 25521,1 & 1018,40 & Q2.18 & 27870,5 & 1112,15 \\
Q3.12 & 23325,3 & 930,78 & Q3.15 & 25720,4 & 1026,35 & Q3.18 & 28066,0 & 1119,95 \\
Q4.12 & 23538,4 & 939,28 & Q4.15 & 25914,3 & 1034,09 & Q4.18 & 28262,0 & 1127,77 \\
\hline
\end{tabular}

Source: Author's calculation

Table 6

Forecasts of Monthly Wage Medians using Random Walk; Conversion rate was set according to the Czech National Bank (CNB) at 31.12.2010 1 EUR $=25.06 \mathrm{CZK}$

\begin{tabular}{lllllllll}
\hline Period & CZK & EUR & Period & CZK & EUR & Period & CZK & EUR \\
\hline Q1.10 & 21912,2 & 874,39 & Q1.13 & 24116,5 & 962,35 & Q1.16 & 26662,6 & 1063,95 \\
Q2.10 & 21107,2 & 842,27 & Q2.13 & 24328,7 & 970,82 & Q2.16 & 26874,8 & 1072,42 \\
Q3.10 & 21632,2 & 863,22 & Q3.13 & 24540,9 & 979,29 & Q3.16 & 27086,9 & 1080,88 \\
Q4.10 & 21887,2 & 873,39 & Q4.13 & 24753,1 & 987,75 & Q4.16 & 27299,1 & 1089,35 \\
Q1.11 & 22419,2 & 894,62 & Q1.14 & 24965,2 & 996,22 & Q1.17 & 27511,3 & 1097,82 \\
Q2.11 & 22631,3 & 903,08 & Q2.14 & 25177,4 & 1004,68 & Q2.17 & 27723,5 & 1106,28 \\
Q3.11 & 22843,5 & 911,55 & Q3.14 & 25389,6 & 1013,15 & Q3.17 & 27935,6 & 1114,75 \\
Q4.11 & 23055,7 & 920,02 & Q4.14 & 25601,7 & 1021,62 & Q4.17 & 28147,8 & 1123,22 \\
Q1.12 & 23267,9 & 928,49 & Q1.15 & 25813,9 & 1030,08 & Q1.18 & 28360,0 & 1131,68 \\
Q2.12 & 23480,0 & 936,95 & Q2.15 & 26026,1 & 1038,55 & Q2.18 & 28572,1 & 1140,15 \\
Q3.12 & 23692,2 & 945,42 & Q3.15 & 26238,3 & 1047,02 & Q3.18 & 28784,3 & 1148,62 \\
Q4.12 & 23904,4 & 953,89 & Q4.15 & 26450,4 & 1055,48 & Q4.18 & 28996,5 & 1157,08 \\
\hline
\end{tabular}

Source: Author's calculation

\section{Modelling of consumer price indices}

The Consumer Price Index is generally recognised as the measure of inflation (Bhattacharya et al. 2008). The indices published are based on the average for 2005 (valid methodology of Czech Statistical Office). The inflation trend is important in for the individual expectations of economic subjects (Hommes et al., 2013). The expected level of inflation has to be used in the indexing of wages, in the estimation of the valuation of long-term orders and also in the provision of loans and credit (Even et al., 1996; Hanes, 2010). In the case that the future level of inflation grows more rapidly than the growth of the Average Gross Monthly Wages or the Monthly Wage Medians, the real growth of wages, wages would still increase, but only nominally, therefore reducing purchasing power.

In order to forecast Consumer Price Indices, we identified the ARIMA Model $(0,2,1)$ with constant and also the Random Walk Model with drift for the time series of Consumer Price Indices. The drift was optimised at the value of 0.564103 . The drift was calculated by an 
iterative method in the system Statgraphics Centurion XVI, version 16.1.11. The estimates of the parameters of the $\operatorname{ARIMA}(0,2,1)$ model with constant are given in Table 7.

\section{Table 7}

Estimates of parameters of the ARIMA $(0,2,1)$ model with constant for the time series of Consumer Price Indices

\begin{tabular}{lllll}
\hline Parameter & Estimate & Stnd. Error & T-Statistic & P-value \\
\hline MA(1) & 1.07262 & 0.0499598 & 21.4697 & 0.000000 \\
Mean & 0.00142017 & 0.00204462 & 0.69459 & 0.491771 \\
\hline Constant & 0.00142017 & & & \\
\hline
\end{tabular}

Source: author's calculation

Figure 5

Behaviour of Consumer Price Indices (Basis - Average for $2005=100$ ) from 1st q. of 2002 to 4th q. of 2010 with predictions calculated up to the 4th q. of 2018 using the ARIMA Model $(0,2,1)$ with constant

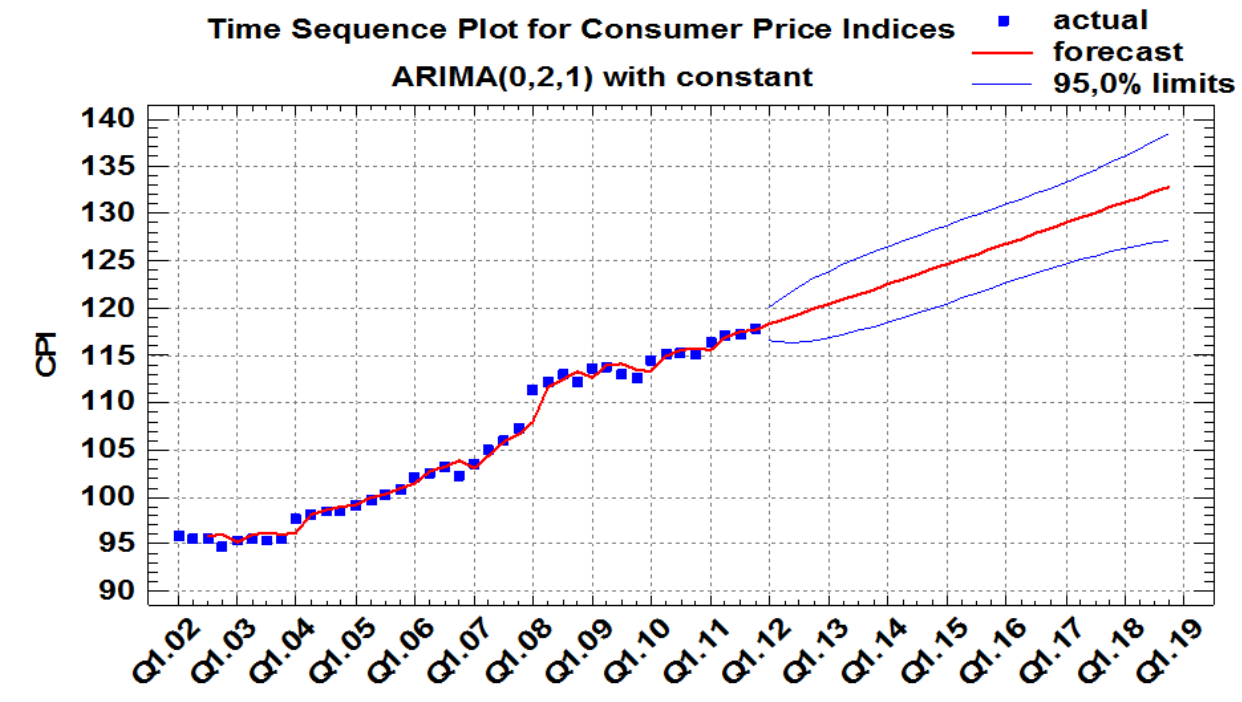

Source: CZSO, Author's illustration

Figure 6

Behaviour of CPI (Basis - Average for $2005=100$ ) from 1st q. of 2002 to 4th q. of 2010 with predictions calculated up to the 4th q. of 2018 using the Random Walk Model with drift

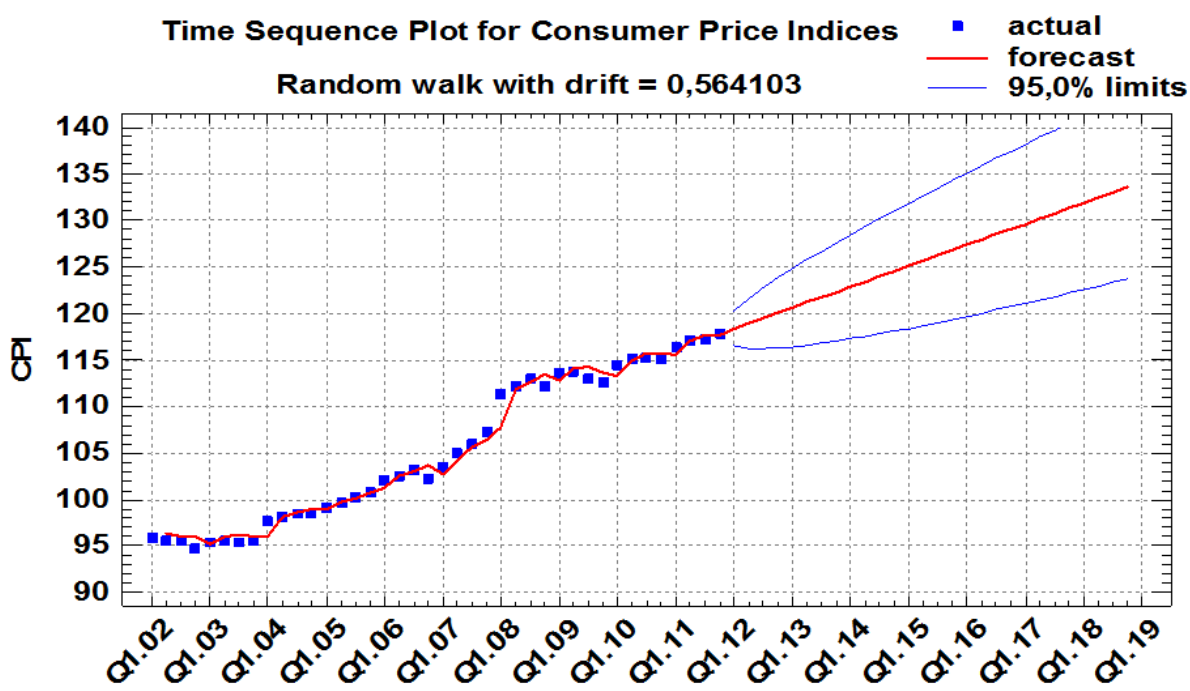

Source: CZSO, Author's illustration 
The diagnostic tests of the model indicate that the non-systematic component of the model is not auto-correlated, is homoscedastic and has normal distribution. Using the model of ARIMA $(1,1,1)$ with constant and the Random Walk Model with a drift of 273.457. The drift was calculated by an iterative method in the system Statgraphics Centurion XVI, version 16.1.11. The predictions were calculated up to the end of 2018 and these are shown in Figure 5 and Figure 6.

The individual models are also divergent to some extent to their forecasts. However, in the discretion of the forecast horizon, it can be argued that it is not significant deviation. In the case of consumer price indices is the difference between the observations in the interval from 0.117 to $0.543 \%$ (compare Figure 5 and 6) and the different value of the difference is also mainly influenced by the assumed quarter.

\section{Comparison of the behaviour of the Consumer Price Index with the behaviour of Average Gross Monthly Wage Indices and Monthly Wage Medians}

For the requirements of the comparison of the behaviour of the Consumer Price Index with the behaviour of Average Gross Monthly Wage Indices, or with the behaviour of Monthly Wage Medians, an average was calculated from the values for the observations from the 1st quarter of 2005 - 4th quarter of 2005. Based on this value, the indices Of Average Gross Monthly Wages or the indices of Monthly Wage Medians were calculated, as presented in the Methodology section of the paper.

These indices, obtained from the ARIMA model and the Random Walk Model, were confronted with the values of the Consumer Price Indices in a multiple X-Y plot. Figure 7 compare Average Gross Monthly Wage Indices and Consumer Price Indices expected behaviour forecasted using ARIMA Model with constant. Figure 8 compare Average Gross Monthly Wage Indices and Consumer Price Indices behaviour forecasted using Random Walk Model. Again, only slight relative differences are evident. However, in the case of a random Walk Model, the imaginary "scissors" between two series of indices opens a little more.

Figure 7

Behaviour of Average Gross Monthly Wage Indices and Consumer Price Indices up to the 4th q. of 2018, ARIMA Model with constant

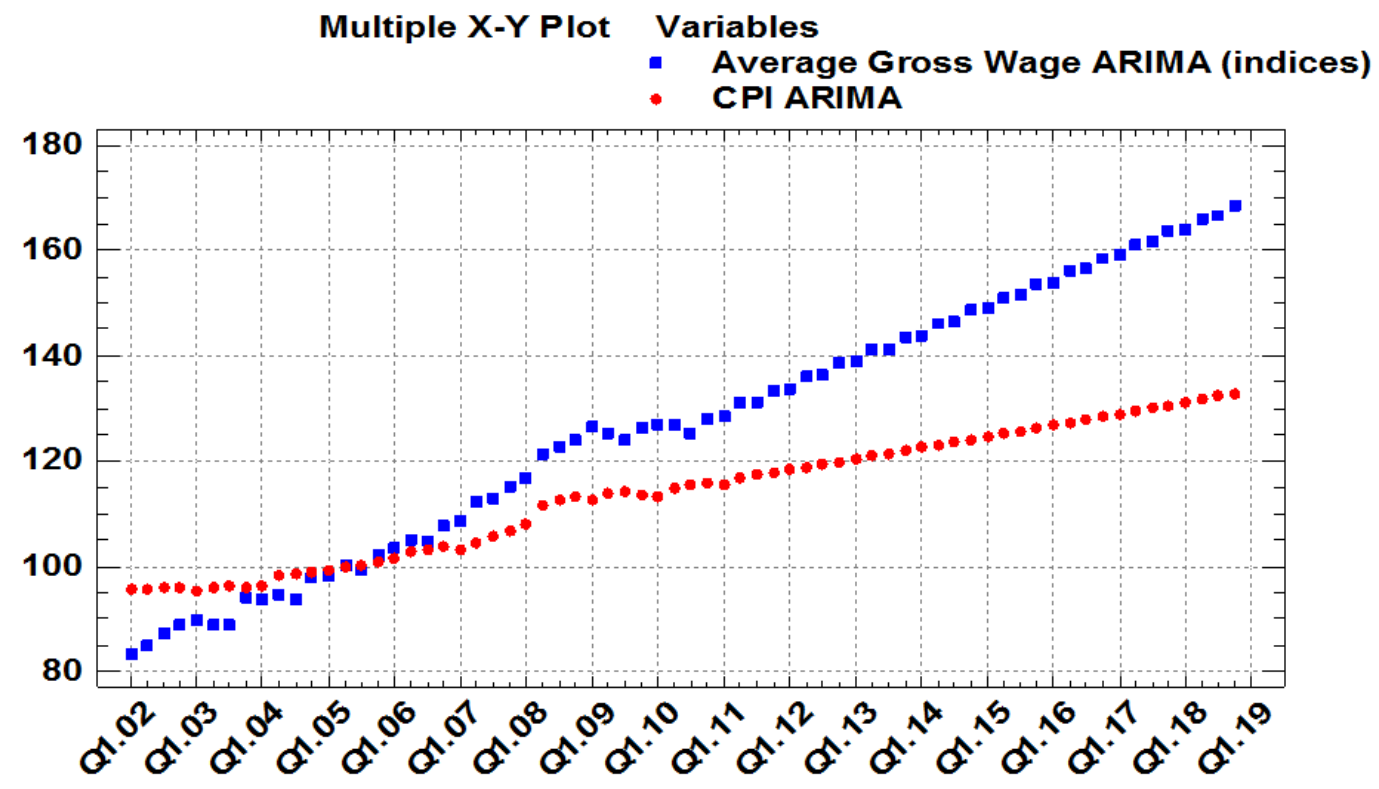

Source: CZSO, ISAE, Author's illustration 
Figure 8

Behaviour of Average Gross Monthly Wage Indices and Consumer Price Indices up to the 4th q. of 2018, Random Walk Model

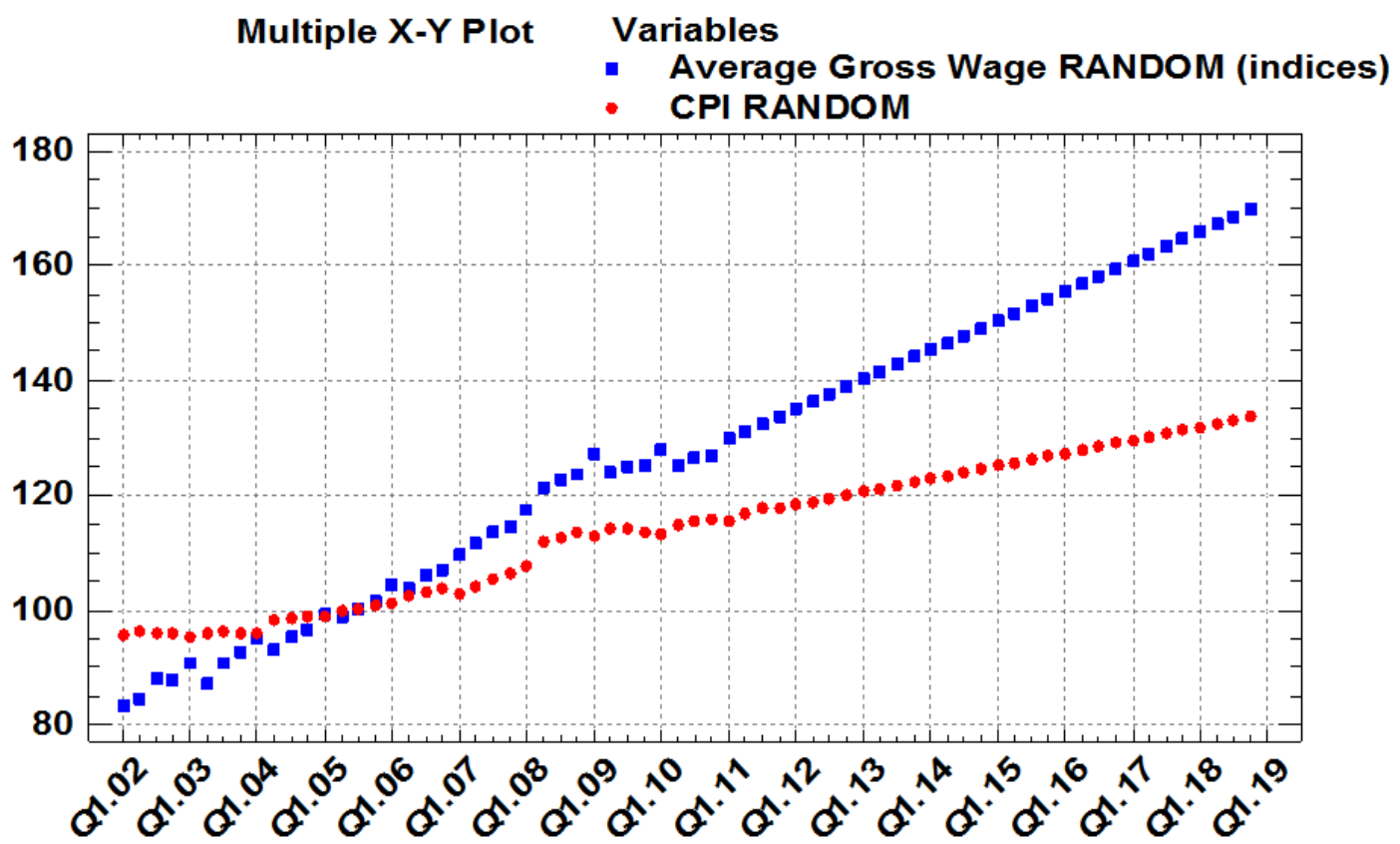

Source: CZSO, ISAE, author's illustration

The confrontation of the values of the Consumer Price Indices with the values of the Monthly Wage Medians Indices is shown in Figure 9 for the ARIMA Model with constant, and in Figure 10 for the Random Walk Model.

Figure 9

Behaviour of Monthly Wage Median Indices and Consumer Price Indices up to the 4th Quarter of 2018, ARIMA Model with constant

Multiple X-Y Plot Variables

- Median Wage ARIMA (indices)

- CPI ARIMA

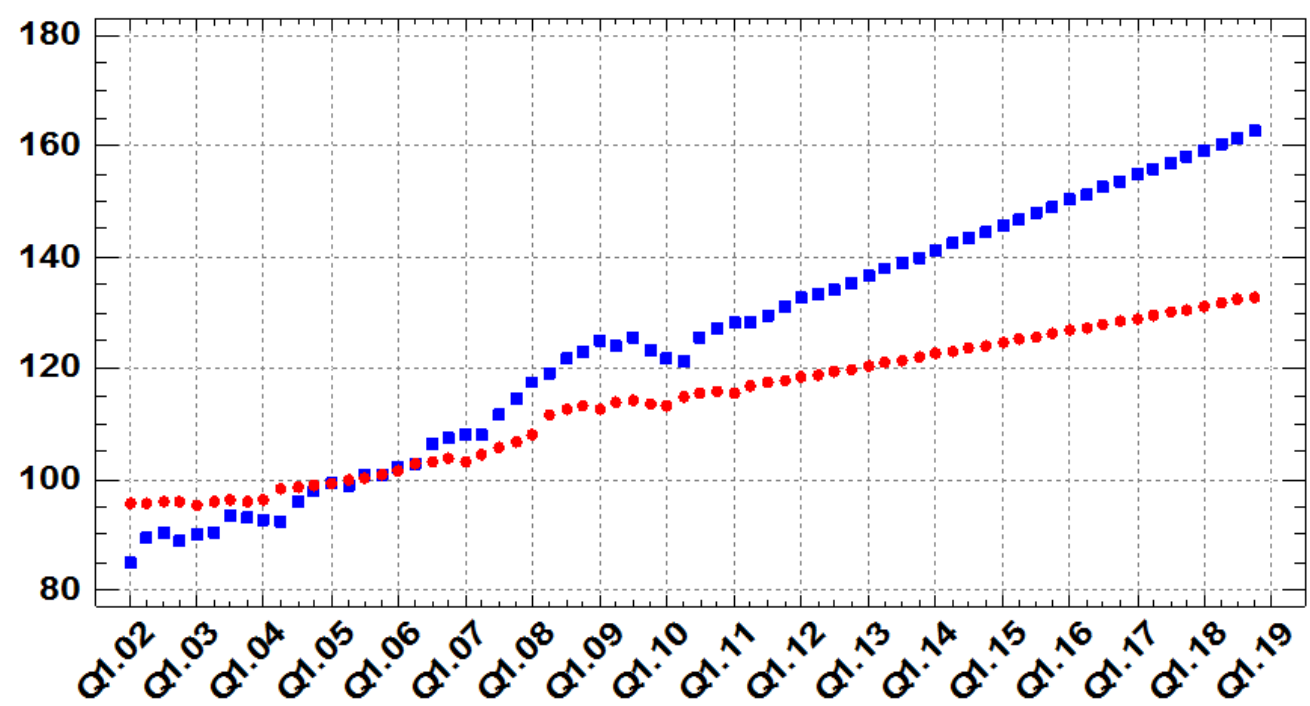

Source: CZSO, ISAE, author's illustration 
Figure 10

Behaviour of Monthly Wage Median Indices and Consumer Price Indices up to the 4th Quarter of 2018, Random Walk Model

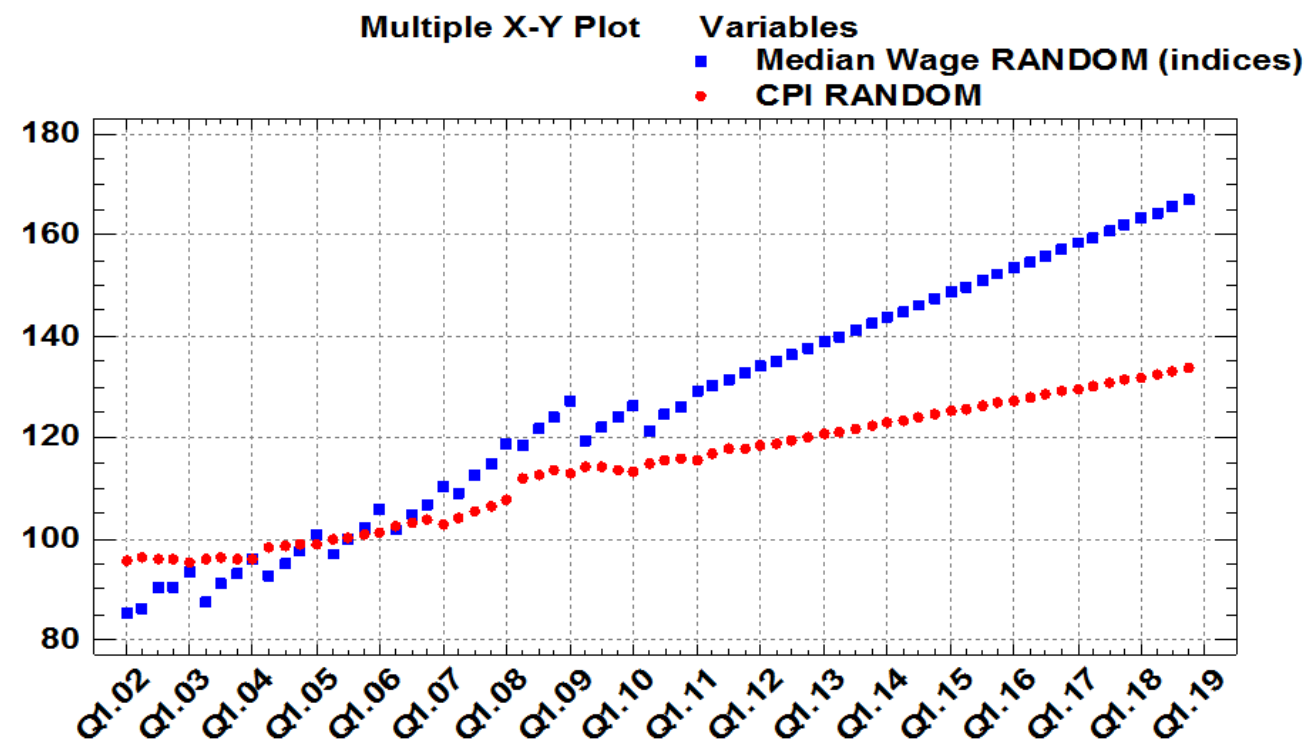

Source: CZSO, ISAE, Author's illustration

\section{Conclusion}

By the end of 2012, the significant recovery of the Czech economy is not generally expected (Janáček et al., 2011; Plašil et al. 2012). If a recovery starts, probably in 2013, it will be determined also by the economic the situation of trade partner countries of the Czech Republic, and the level of the recovery from the crises in entire European Union. In the case that the recovery occurs, the first who recognize the increase in gross monthly wages will be the employees of the business sector. The employees of non-business sector have their wages long-term fixed at the specific tariffs and eventual recovery of the economy will need to have a longer-period than become to change the tariffs. This is mainly the reason why this work is focused on the Czech business sphere.

Results of our research revealed following conclusions. Assuming ceteris paribus, it is to be expected that the Average Gross Monthly Wages and Monthly Wage Medians in the business sector of the Czech Republic will rise. The Consumer Price Indices, indicating aggregate price level of the domestic economy, will also rise. Due to the point that the speed of the rising trend of Average Gross Monthly Wages and Monthly Wage Medians might be higher than the rate of growth of inflation, it is possible to forecast with high certainty that real wages may continue to grow in the business sector in the future. However, to our knowledge none of the public institutions in the Czech Republic attempted so far to compare the future evolution of Consumer Prices Indices and wages, using any statistical techniques. Therefore, this paper presents a novel approach to forecasting future salaries' level, using stochastic modelling in the Checz Republic.

\section{References}

1. Bhattacharya, P.S., Thomakos, D.D. (2008), "Forecasting industry-level CPI and PPI inflation: Does exchange rate pass-through matter?" International Journal of Forecasting, Vol. 24, No. 1, pp. 134-150.

2. Box, G.E.P., Jenkins, G. (1970), Time series analysis: Forecasting and control, San Francisco, Holden-Day.

3. Bucevska, V. (2012), "An Empirical Evaluation of GARCH Models in Value-at-Risk Estimation: Evidence from the Macedonian Stock Exchange", Business Systems Research, Vol. 4, No.1, pp. 49-64. 
4. Engle, R.F. (1995), ARCH: selected readings, Oxford: Oxford University Press.

5. Evans, G.W., Honkapohja, S. (2001), Learning and Expectations in Macroeconomics. Princeton: Princeton University Press.

6. Even, W.E., MacPherson, D.A. (1996), "Consequences of minimum wage indexing", Contemporary Economic Policy, Vol.14, No.4, pp.67-77.

7. Hanes, Ch. (2010), "The rise and fall of the sliding scale, or why wages are no longer indexed to product prices", Explorations in Economic History, Vol.47, No.1, pp. 49-67.

8. Hommes, C., Lux, T. (2013), "Individual expectations and aggregate behavior in learning to forecast experiments", Macroeconomic Dynamics, Vol.17, No.2, pp. 373-401.

9. Ivanov, O., Vaseashta, A. (2013), "A method for fast and contactless control of raw materials", Ceramics International, Vol. 39, No. 3, pp. 2903-2907.

10. Janáček, K., Komárková, Z., Hlaváček, M., Komárek, L. (2012),"Impacts Of The Sovereign Default Crisis On The Czech Financial Sector" Czech National Bank: Financial Stability Report, pp. 118-128.

11. Jarque, C.M., Bera, A.K. (1980), „Efficient tests for normality, homoscedasticity and serial independence of regression residuals", Economics Letters, Vol. 6, No. 3, pp. 255-259.

12. Jeřábková, V., Zelený, M. (2011), "Czech Labour Market Development in the Period of the Recent Economic Downturn - A Combined View from the Employment and Wage Statistics", in Zdrój, L. (Ed) (2011), AMSE - Applications of Matematics and Statistics in Economy. Wroclaw: Uniwersytet Ekonomiczny.

13. Langhamrová, J., Šimpach, O. (2012), "The Income Inequality of Business and Nonbusiness Sphere in the Czech Republic", In: Nerovnost a chudoba v Európskej únii a na Slovensku. Košice : Ekonomická fakulta TU, pp. 113-122. Text in Czech.

14. Montiel, P., Servén, L. (2006), "Macroeconomic Stability in Developing Countries: How Much Is Enough?", World Bank Research Observer, Vol. 21, No. 2, pp. 151-178.

15. Okafor, L. E., Tyrowicz, J. (2010), "Saving less when there is more foreign lending? Foreign debt and savings in developing countries", Journal of Economic Policy Reform, Vol. 13, No. 3, pp.213-223.

16. Pejić-Bach, M. (2003), "Surviving in an environment of financial indiscipline: a case study from a transition country." System Dynamics Review, Vol. 19, No. 1, pp. 47-74.

17. Plašil, M., Kubicová, I. (2012), "Contingent Claims Analysis And The Inter-Sector Transmission Of Credit Risk." Czech National Bank: Financial Stability Report, pp. 129-139.

18. Shepherd, B. (2012), "When are adaptive expectations rational? A generalization", Economics Letters, Vol. 115, No. 1, pp. 4-6.

19. Smrčka, L., Arltová, M. (2012), "Increasing Threat of a "Total Financial Crisis" in the Upcoming Years." International Journal of Mathematical Models and Methods in Applied Sciences, Vol. 6, No. 1, pp. 782-790.

20. Šimpach, O, Langhamrová, J. (2012), "The Expected trends in the Development of Employment. The Prediction of Employed Persons in Selected Non-manufacturing Sectors". Fórum sociální politiky, Vol. 6, No. 4, pp. 11-17.

21. van den Berg, R., Ma, W.J. (2012), "Robust averaging during perceptual judgment is not optimal", Proceedings of the National Academy of Sciences of the United States of America, Vol. 109, No. 13, pp. 13341-13346.

22. Zelený, M. (2001), "A view of income poverty in the CR, using EU methodology“. Statistika, Vol. 38, No. 11, pp. 458-467. 


\section{About the authors}

Ondřej Šimpach is an internal PhD student at the University of Economics Prague, Faculty of Informatics and Statistics, Department of Demography. He teaches basic statistics courses, and basic and advanced courses of demography, such as economic demography, regional demography, actuarial demography, etc. His research interests include statistics, econometrics, demographic development and population aging. Author can be contacted at ondrej.simpach@vse.cz

Jitka Langhamrová is Full Docent and Head of the Department of Demography at the University of Economics in Prague, Faculty of Informatics and Statistics. She is the guarantor of most of the demographic courses and teaches e.g. economic and regional demography. Her research interests include population development and socio-economic consequences of population aging. She is the mentor of $5 \mathrm{PhD}$ students. Author can be contacted at langhamj@vse.cz 